\title{
SEGUINDO OS TRAÇOS DA EPISTEME MODERNO/COLONIAL NO DOCUMENTO CURRICULAR DO ESTADO DO PARÁ
}

\author{
SIGUIENDO LAS HUELLAS DE EPISTEMAS MODERNOS/COLONIALES EM EL \\ DOCUMENTO CURRICULAR DEL ESTADO DE PARÁ
}

\author{
FOLLOWING THE TRACES OF MODERN/COLONIAL EPISTEMS IN THE \\ CURRICULAR DOCUMENT OF THE STATE OF PARÁ
}

\author{
Joyce Otânia Seixas RIBEIRO 1
}

\begin{abstract}
RESUMO: Este artigo tem como objetivo analisar a política curricular do estado do Pará, considerando a episteme moderno/colonial. O aporte teórico é o do giro decolonial com Mignolo (2003; 2005; 2007; 2008; 2014), Castro-Gómez (2005a; 2005b; 2007), Palermo (2014), e dos estudos curriculares com Silva (1999), Macedo (2014; 2015) e Lopes (2004; 2008; 2019). O campo de investigação é o Documento Curricular do Estado do Pará, e a arte do fazer é a etnografia multilocal, um procedimento emergente para a análise de documentos (MARCUS, 2001). Os resultados indicam que dois traços da episteme moderno/colonial se destacam, a estrutura disciplinar e a homogeneização cultural, produzindo um documento curricular inconsistente. Indico como razão de tal inconsistência curricular o fato de os agentes estatais terem conduzido a metodologia de elaboração do Documento Curricular do Estado do Pará por meio de excessiva obediência epistêmica, bem como por terem excluído a sociedade civil organizada e as comunidades tradicionais do processo. Concluo argumentando que a desobediência epistêmica é capaz de produzir uma política do conhecimento outra, orientada pela política do lugar, pela transdisciplinaridade e pela interculturalidade.
\end{abstract}

PALAVRAS-CHAVE: Episteme moderno/colonial. DCEPará. Estrutura disciplinar. Homogeneização cultural. Desobediência epistêmica.

RESUMEN: Este artículo tiene como objetivo analizar la politica curricular del estado de Pará, considerando la episteme moderno/colonial. El aporte teórico es el del giro decolonial con Mignolo (2003; 2005; 2007; 2008; 2014), Castro-Gómez (2005a; 2005b; 2007), Palermo (2014), y de estudios curriculares con Silva (1999), Macedo (2014; 2015) y Lopes (2004; 2008; 2019). El campo de investigación es el Documento Curricular del Estado de Pará, y el arte de hacer es la etnografía multilocal un procedimiento emergente para el análisis de documentos (MARCUS, 2001). Los resultados indican que se destacan dos rasgos de la episteme moderno/colonial, la estructura disciplinaria y la homogeneización cultural, produciendo un documento curricular inconsistente. Indico como razón de tal inconsistencia curricular el hecho de que los agentes estatales hayan conducido la metodología de elaboración del Documento Curricular del Estado de Pará a través de una excesiva obediencia epistémica, así como por haber excluido del proceso a la sociedad civil organizada y las comunidades tradicionales. Concluyo argumentando que la desobediencia

\footnotetext{
${ }^{1}$ Universidade Federal do Pará (UFPA), Abaetetuba - PA - Brasil. Professora da Faculdade de Educação e Ciências Sociais e Professora do Programa de Pós-Graduação em Cidades: Territórios e Identidades. Doutorado em Educação (UFPA). ORCID: https://orcid.org/0000-0002-1323-3554. E-mail: joyce@ufpa.br
} 
epistémica es capaz de producir una política de conocimiento diferente, guiada por la política del lugar, la transdisciplinariedad y la interculturalidad.

PALAVRAS CLAVE: Episteme moderno/colonial. DCEPará. Estructura disciplinaria. Homogeneización cultural. Desobediencia epistémica.

ABSTRACT: This paper aims to analyze the curricular policy of the state of Pará, considering the modern/colonial epistemic. The theoretical contribution is that of the decolonial overturn with Mignolo (2003; 2005; 2007; 2008; 2014), Castro-Gómez (2005a; 2005b; 2007), Palermo (2014), and of the curricular studies with Silva (1999), Macedo (2014; 2015), and Lopes (2004; 2008; 2019). The field of investigation is the Documento of the State of Pará, and the art of doing is multifocal ethnography, an emerging producer for the analysis of documents (MARCUS, 2001). The results indicate that two features of the modern/colonial epistemic stand out, the disciplinary structure and the cultural homogenization, producing an inconsistente curriculum document. I indicate as a reason for such curricular inconsistency the fact that the state agents have conducted the methodology of elaboration of the Curricular Document of the State of Pará through excessive epistemic obedience, as well as for having excluded organized civil society and traditional communities from the process. I conclude by arguing that epistemic disobedience is capable of producing a different knowledge policy, guided by the politics of place, transdisciplinarity and interculturality.

KEYWORDS: Modern/colonial episteme. DCEPará. Disciplinary structure. Cultural homogenization. Epistemic disobedience.

\section{Introdução}

Este artigo tem como objetivo seguir dois traços da episteme moderno/colonial presentes na política curricular do estado do Pará e, neste movimento, conto com as contribuições do giro decolonial, dialogando com Mignolo (2003; 2005; 2007; 2008; 2014), Castro-Gómez (2005a; 2005b; 2007), Palermo (2014), bem como com Silva (1999), Macedo $(2014 ; 2018)$ e Lopes $(2004 ; 2008 ; 2019)$ no campo dos estudos curriculares.

Penso que convém esclarecer brevemente sobre o giro decolonial. Trata-se de um movimento político, teórico e ético que vem sendo constituído por uma comunidade de argumentação com intelectuais da América Latina, como Aníbal Quijano, Walter Mignolo, Ramón Grosfoguel, Nelson Maldonado-Torres, Arturo Escobar, Santiago Castro-Gómez, Zulma Palermo, María Lugones, Catherine Walsh, e muitos outros. Este movimento se iniciou no final da década de 1990, tendo se consolidado como uma alternativa crítica para pensar saídas aos problemas da região. Esta comunidade de argumentação parte do pressuposto de que a modernidade é produto do colonialismo e das quatro estratégias coloniais ${ }^{2}$,

${ }^{2}$ Colonialidade do poder, colonialidade do saber, colonialidade do ser e colonialidade de gênero. 
intencionando visibilizar seu lado obscuro - os problemas sociais, epistemológicos e ontológicos -, e interromper o domínio colonial na América Latina. Com esta intenção, o giro decolonial tece críticas as teorias liberais, críticas e pós-críticas por considerar que estas ignoram os efeitos do colonialismo na política do lugar e na política do conhecimento. Considerando disso, seu desafio tem sido produzir ferramentas analíticas não-eurocêntricas capazes de auxiliar na constituição de uma episteme e uma arte de viver outra nesta região.

Quanto ao método, em outro lugar ${ }^{3}$ apresentei com mais vagar a etnografia multilocal e, agora, em razão do espaço, serei breve. A etnografia multilocal é uma arte do fazer emergente, contestada, mas produtiva, que surgiu na década de 1980 como resposta às crises epistêmica e contextual contemporâneas (MARCUS, 2001; MARCUS; FISHER, 2000), expressas na diluição das culturas e no desaparecimento de povos nativos, objetos clássicos da Antropologia. Foi decisivo na opção metodológica pela etnografia multilocal o fato de esta ser marcada pelo rastreio de formações culturais em espaços inusitados no sistema-mundo, palavra-chave do giro decolonial. Há duas modalidades de etnografia multilocal e, aqui, desenvolverei aquela que se ocupa do estudo de arquivos, mais precisamente de documentos. Como os documentos constituem parte do estado moderno, foi imperativo acionar a noção de estado e de burocracia, na medida em que o aspectos regulatórios são centrais (ABRAMS, 2014).

Nesta perspectiva, documentos são considerados espaços sociais definidos por interesses políticos específicos na condução da instituição estatal, por condensarem uma multiplicidade de experiências sociais, o que os torna fonte privilegiada de informação (ZARIAS, 2004, p. 01). Aqui, o documento analisado é o Documento Curricular do Estado do Pará. A arte do fazer consiste em rastrear o discurso, a metáfora e a trama (MARCUS, 2001) que produzem certo documento, mas há outros procedimentos relativos ao manuseio de documentos destacados por Zabala (2010), bem como por Muzzopappa e Villalta (2011), a serem observados. A postura da pesquisadora é orientada por uma ética cujo princípio é "o pessoal é político", o que constitui identidades e subjetividades voláteis, e permite estranhar o trivial (ZABALA, 2010).

$\mathrm{Na}$ tentativa de alcançar o objetivo indicado, organizei o artigo partindo da organização do conhecimento no DCEPará, para, em seguida, me deter nos dois traços da episteme moderno/colonial presentes no documento: a estrutura disciplinar e a homogeneização cultural. Encerro apontando a desobediência epistêmica como possibilidade

\footnotetext{
${ }^{3}$ Artigo intitulado A política de identidade do Documento Curricular do Estado do Pará. Revista Estudios sobre las culturas contemporáneas, Colima, Época III, v. XXVI, n. 52, pp. 9-36, jan./jun. 2021.
} 
para elaborar uma política de conhecimento orientada pela política do lugar, pela interculturalidade e pela transculturalidade, o que já é realidade na Bolívia, Venezuela e Equador.

Convém, ainda, frisar que mesmo estando ciente da consolidação dos estudos curriculares no Brasil, decidi aceitar a provocação de Tomaz Tadeu da Silva (1999) sobre o imperativo de descolonizar o currículo. O curriculista gaúcho prepara o caminho para a realização desta tarefa, porém, o faz por meio da teoria pós-colonial; aqui, aposto na experimentação acionando as ferramentas analíticas do giro decolonial, uma episteme-emformação envolvente e potente. De tudo, só no ensaio e no erro é possível inventar novas trilhas.

\section{A organização do conhecimento no Documento Curricular do Estado do Pará}

Após a aprovação da Base Nacional Comum Curricular - BNCC no ano de 2018, teve início o processo de implementação para o qual todas as Unidades da Federação foram ampla e intensamente mobilizadas, de modo que até o momento, vinte e um estados e o Distrito Federal já reformularam os currículos da educação infantil e do ensino fundamental ${ }^{4}$ alinhados à Base. Assim, a Secretaria de Estado de Educação - SEDUC/Pa, aderiu a apoiou a implementação da BNCC, argumentando que: “[...] o MEC convocou os estados para realizar a implementação da referida Base visto que a mesma passa a ser a referência nacional e obrigatória para a (re)formulação dos currículos" (PARÁ, 2018, p. 12, grifo meu), a partir de objetivos de aprendizagem e de habilidades propostas pela $\mathrm{BNCC}$, considerada referência obrigatória. Não me deterei nos problema relativos a adesão à $\mathrm{BNCC}$, pois estes têm sido amplamente debatidos e dizem respeito à lógica da política curricular nacional, marcada pelo ideário neoliberal e pela pedagogia instrumental.

Desse modo, no Pará, várias ações foram realizadas para que as redes de ensino pudessem contar com currículos adaptados à BNCC. O processo envolveu os agentes estatais (equipe técnica) e professores-professoras em um conjunto de atividades visando a reformulação do currículo local, bem como mudanças na avaliação, nos materiais didáticos e na formação continuada de docentes. O Documento Curricular do Estado do Pará/DCEPará foi elaborado sob a coordenação de uma equipe técnica da Secretaria de Estado de Educação do Estado do Pará - SEDUC/Pará e, mesmo contestado, foi aprovado em dezembro de 2018, pelo Conselho Estadual de Educação - CEE/Pará, sendo disponibilizado no portal da SEDUC/

\footnotetext{
${ }^{4}$ Disponível em: http://www.consed.org.br/consed/implementacao-da-bncc-nos-estados. Acesso em: 15 dez. 2020.
} 
Pará $^{5}$. O documento curricular é apresentado em 462 páginas e organizado em cinco partes. Na capa, chama a atenção as várias imagens em alusão à multiplicidade da cultura paraense, na clara intenção de estabelecer vínculo entre território, cultura e educação.

Antes de apresentar a organização do conhecimento para a educação infantil e o ensino fundamental, o documento em análise situa o contexto histórico contemporâneo, marcado por intensas mudanças sociais e cognitivas, bem como suas consequências nas várias dimensões da vida.

Na sociedade contemporânea vivemos um tempo de intensas mudanças: a dinâmica do trabalho, a maneira como as pessoas interagem, a vida cotidiana e até mesmo o pensamento estão num apelo que solicita aos sujeitos expandirem sua maneira de ver e atuar no mundo e quebrar o olhar padrão sobre as coisas (PARÁ, 2018, p. 13, grifo meu).

[...] a visão moderna de conhecimento que, derivada da especialização, fragmentou-o em especialidades, perdendo assim a visão de totalidade separando os que sabem 'cientistas' dos que não sabem cidadãos comuns (FERNANDES, 2007 apud PARÁ, 2018, p. 13).

O documento curricular reconhece que as mudanças socioculturais resultaram dos avanços civilizatórios, e que estes também produziram desigualdades sociais, econômicas, culturais, assim como problemas epistêmicos. Neste último caso, os problemas foram ocasionados pela visão moderna de conhecimento que fragmentou o saber, separou os que sabem dos que não sabem, valorizou os saberes científicos e invisibilizou os saberes populares, levando à perda da visão de totalidade (PARÁ, 2018). O documento curricular informa que tais problemas impõem a necessidade de mudanças. Assim, sugere que as desigualdades sociais e a compartimentação do saber podem ser sanadas por duas ações, uma epistêmica e outra pedagógica. A primeira se expressa na indicação de quebrar o olhar de modo a alterar a forma de ver o conhecimento; a segunda diz respeito à prática pedagógica interdisciplinar; ambas são consideradas necessárias para superar a compartimentação e valorizar a diversidade.

A noção de currículo acionada no documento em tela é a de construção social, logo, o currículo é emancipatório e resultado de seleção cultural conflituosa em razão do controle social. Por outro lado, é perceptível certa inter-relação entre currículo, experiências escolares e identidades. Neste sentido, o currículo traduz-se nas próprias

[...] experiências escolares que se desdobram em torno do conhecimento, em meio a relações sociais, e que contribuem para a construção das identidades de nossos/as estudantes. Currículo, associa-se, assim, ao conjunto de

\footnotetext{
${ }^{5}$ Portal SEDUC/Pará. Disponível em: http://www.seduc.pa.gov/site/seduc. Acesso em: 15 dez. 2020.
} 
esforços pedagógicos desenvolvidos, com intenções educativas, nas instituições escolares (MOREIRA; CANDAU, 2007, p. 21 apud PARÁ, 2018, p. 16).

No trecho acima fica clara a relação entre experiência, conhecimento e identidades, por isso, o DCEPará insiste no argumento de que as intenções educativas da escola precisam distanciar-se de práticas descontextualizadas e compartimentadas. Para concretizar a noção de currículo como construção social e seu vínculo com as experiências cotidianas que constituem identidades, o documento tenta se distanciar do currículo tipo coleção - sugerindo acompanhar a crítica ao currículo formulada por Basil Bernstein -, pois esta modalidade de currículo fragmenta e isola os conhecimentos. Para o documento em análise, o currículo ideal é o construído coletivamente por ser capaz de expressar identidades.

Com o terreno preparado, o DCEPará apresenta a organização do conhecimento realizada a partir de eixos estruturantes, considerados campos temáticos capazes de mobilizar os conhecimentos eleitos na escola para serem tratados cientificamente e confrontados com os saberes produzidos por homens e mulheres, como na passagem a seguir:

O documento curricular do estado do Pará apresenta como concepção de organização do conhecimento os eixos estruturantes, tal qual são apresentados pelas DCNEI (BRASIL, 2010a) e pela própria BNCC (BRASIL, 2017a), estes se configuram como campos temáticos amplos e privilegiados, capazes de mobilizar conhecimentos/conteúdos eleitos na escola e tratados cientificamente, no confronto com saberes produzidos historicamente e reelaborados [sic] por homens e mulheres (PARÁ, 2018, p. $63)$.

Os eixos estruturantes organizam tanto a educação infantil quanto o ensino fundamental. Na educação infantil, as interações e as brincadeiras subsidiam a aprendizagem e o desenvolvimento, e são consideradas como capazes de garantir os direitos de aprendizagem das crianças - direitos de conviver, brincar, participar, explorar, expressar e conhecer. No ensino fundamental, os eixos estruturantes são: Espaço/Tempo e suas Transformações, Linguagem e Suas Formas Comunicativas, Valores à Vida Social, e, por fim Cultura e Identidade. Há a previsão de Ciclos de Aprendizagem com fluxos mais flexíveis, e componentes curriculares da tradição pedagógica, como Língua Portuguesa, Educação Física, Arte, Língua Inglesa, História, Geografia, Estudos Amazônicos, Ciências, Matemática e Ensino Religioso.

Ao rastrear o documento guiada pelo giro decolonial, avancei rastreando a episteme moderno/colonial, e identifiquei dois de seus traços, que passarei a explorar. 


\section{O DCEPará: estrutura disciplinar e homogeneização cultural}

Apesar de perceber que há muitos traços para a reflexão, me deterei em apenas dois, a estrutura disciplinar e a homogeneização cultural. O primeiro traço fica expresso quando o documento critica o currículo do tipo coleção e a compartimentação do saber, propondo organizar o conhecimento em eixos estruturantes e campos de experiência; porém, este intento não se materializa, pois o conhecimento acaba sendo organizado na tradicional estrutura disciplinar, arbórea e canônica.

Na educação infantil é perceptível a dificuldade de pensar uma organização alternativa à estrutura disciplinar, logo, o documento se mantém no lugar comum dessa lógica, ao associar os campos de experiência a campos de saber como o numeramento, a linguagem oral e escrita, hierarquizando o conhecimento. Ao refletir sobre a lógica de organização do conhecimento para a educação infantil, Tiriba e Flores (2016) reafirmam que a concepção curricular precisa ter como eixo as interações e as brincadeiras, e destacam que a estrutura disciplinar com foco no letramento e no numeramento tem a intenção de facilitar a avaliação em larga escala prevista na BNCC.

No Ensino Fundamental não é diferente, aliás, a estrutura disciplinar, arbórea e canônica é confirmada pelos componentes curriculares previstos. A estrutura disciplinar compartimentada fica clara nas fronteiras disciplinares bem definidas, sugerindo limites que não devem ser ultrapassados, o que pode dificultar o diálogo e as trocas. A organização curricular é arbórea em razão da existência de disciplinas hierarquizadas, na medida em que alguns componentes curriculares são considerados mais relevantes, como Português e Matemática, o que é comprovado pelo quantitativo mais elevado de objetivos e de habilidades esperadas, ao contrário dos componentes curriculares considerados menos relevantes, como Educação Física e Ensino Religioso, por exemplo.

Em relação ao cânone, este é mantido do mesmo modo como disposto na BNCC. O cânone se expressa na indicação de temas e obras consideradas clássicas e indispensáveis na tradição pedagógica ocidental. Tiriba e Flores (2016) questionam o cânone expresso na exclusividade de referências paradigmáticas ocidentais, no detrimento dos conhecimentos das comunidades tradicionais brasileiras. É assim em razão do cânone ser constituído por um conjunto de obras reconhecidas por seu valor cultural e científico, logo, obras que não atendam a este critério são descartadas por serem consideradas irrelevantes, como é o caso de obras elaboradas por autores/as de grupos minoritários (FRANCO, 2008). A seleção do cânone é realizada por intelectual com autoridade para tal, ação que não é neutra e/ou 
asséptica, mas informada pelo contexto social, político e cultural de cada período histórico, bem como por gênero, raça e classe social. No fim, o cânone é a expressão do universalismo abstrato e do eurocentrismo, devendo ser seguido pela nação que quer ser representada como civilizada.

Sobre a estrutura disciplinar, Lopes (2008) destaca que na sociedade ocidental o currículo disciplinar é hegemônico, fato que não impede outras formas de organização do conhecimento. Apesar de a autora argumentar que nos últimos vinte anos é perceptível certa flexibilização curricular, com organização contextualizada e interdisciplinar do conhecimento, a política do conhecimento no Brasil tem sido marcada pela ambivalência na medida em que recupera tradições curriculares instrumentais (como a BNCC), o que permite a crítica às disciplinas escolares, consideradas retrógradas e descoladas da vida dos estudantes.

Nesta cena, as disciplinas escolares tem sido representadas como descontextualizadas, fragmentadas e empecilhos para a diversificação do sistema de ensino. Apoiando-se em argumentos de Ivor Goodson, para quem as disciplinas definem a organização da estrutura educacional (orientam certas exigências sócio educacionais como a produção de diplomas, a formação de professores, o trabalho docente) por meio da produção de discursos que são sustentados e sustentam comunidades disciplinares, Lopes (2008) conclui que as disciplinas escolares não são "boas" ou "ruins", "certas" ou "erradas" em si, pois são instituições educativas com as quais se negocia a significação da política curricular. Assim sendo, a intenção dos sistemas de ensino de quebrar a disciplinaridade poderá se revelar inalcançável, caso as ações não sejam capazes de garantir o diálogo com as comunidades disciplinares. Em artigo recentemente publicado, Lopes (2019) esclarece, mais uma vez, que as disciplinas não são intocáveis, mas salienta que a reorientação da organização curricular não pode se limitar a alterar a listagem de conteúdos, competências e habilidades, mas precisa considerar as práticas discursivas e as identidades docentes. No fim, a autora afirma que a organização disciplinar não é, necessariamente, um mal a ser superado.

Quanto ao segundo traço, a homogeneização cultural, ao rastrear o documento curricular em análise, mapeei discursos ancorados em teorias educacionais críticas, metáforas que traduzem intenções sócio educacionais e políticas, como construção, quebrar o olhar, pilar fundador, bem como a trama da qual é indissociável. Sobre a trama política, esta foi bem articulada durante o processo de elaboração do DCEPará, com reuniões, encontros e seminários preparatórios consultivos, cujos participantes foram apenas os professores e as professoras da rede, ou seja, as comunidades disciplinares. A trama política foi excludente na medida em que impediu a participação efetiva da sociedade civil organizada e das 
comunidades tradicionais. Esta é a razão da homogeneização promovida pelo documento, pois não é possível enfrentá-la com práticas hierárquicas, burocratizantes e excludentes como as desta metodologia de elaboração meramente consultiva. Porém, diante da exclusão, a sociedade civil organizada resistiu e se insurgiu ocupando a plenária da sessão do Conselho Estadual de Educação, impedindo a aprovação do documento (foi aprovado em outra sessão). O processo de elaboração e o documento curricular foram criticados pelo Manifesto em Defesa da Educação Pública (2018), e há várias reportagens nos jornais locais e blogs que divulgaram o conflito. O combate à homogeneização cultural só é possível mediante a garantia da efetiva participação dos grupos excluídos, de modo a estabelecer o diálogo e a escuta às suas demandas culturais e epistêmicas.

A despeito desta metodologia de elaboração excludente, o documento curricular insiste no discurso sobre diversidade, clamando por valorização cultural, respeito e reconhecimento dos saberes, como em passagens como esta:

Toda política curricular deve ter na cultura sua baliza, pois é fruto da seleção e produção de saberes, das manifestações culturais, dos embates e parcerias entre pessoas, concepções de conhecimento e aprendizagem e formas de imaginar e perceber o mundo (PARÁ, 2018, p. 99, grifos meus).

Considerar os conhecimentos ancestrais como saberes é uma forma de inferiorizá-los, pois, para Mignolo $(2005 ; 2008)$, a episteme moderno-colonial hierarquiza conhecimento e saber, de modo que o conhecimento verdadeiro e universal é sempre aquele produzido pela racionalidade científica europeia; por outro lado, os saberes são considerados irrelevantes porque elaborados pelos povos colonizados, bárbaros, logo, sem habilidades cognitivas para produzir conhecimentos. O apagamento das diferenças se concretiza pela defesa da similiaridade humana, na medida em que todos são considerados como iguais no mundo.

Wallerstein (2004) argumenta que a homogeneização cultural é uma estratégia central de apagamento das culturas nativas e das diferenças, materializada por meio da imposição de políticas culturais uniformizadoras - como as reformas curriculares - às nações periféricas e semi periféricas, como o Brasil; no fim, a homogeneização cultural garante a coesão social e a acumulação incessante no sistema-mundo contemporâneo. No caso brasileiro, Gabriel (2015), destaca que a finalidade última de um currículo homogeneizador é o de unificar a nação por meio de uma cultura comum nacional, e este intento foi concretizado por um esquema político entre a elite nativa, os empresários, a direita política brasileira e os agentes estatais, todos comprometidos com a a acumulação do capital. 
Ainda da perspectiva da estrutura estatal e de sua conexão com o sistema-mundo moderno/colonial, o estado neutro e objetivo é uma ilusão, pois sua pesada máquina burocrática com documentos, rituais, normas e interesses definem um poder temeroso e de longa duração (WEBER, 1999). A burocracia estatal é pesadamente racional com foco na ordem e na hierarquia; em razão disso, as massas são impedidas de participar das decisões, por serem consideradas irracionais, logo, promoverem a desorganização e diluirem a hierarquia.

A mentalidade burocrática, o discurso indolente e improdutivo dos agentes estatais conduziram a elaboração do DCEPará, dificultando efetivas mudanças na organização do conhecimento. No fim, a política de conhecimento do estado do Pará segue com uma identidade política em sintonia com a episteme moderno/colonial do atual mundo, marcado pela globalidade imperial pós-11 de setembro de 2001, que privilegia a educação compartimentada, monolíngue e monocultural.

\section{A violência epistêmica e seus efeitos no conhecimento e nas culturas}

Os argumentos de Lopes $(2008 ; 2019)$ de que as disciplinas não se constituem em um problema a ser superado difere da analítica do giro decolonial pois, nesta perspectiva, as disciplinas estão implicadas no projeto de colonização das Américas. Assim, nesta parte pretendo explorar um pouco mais sobre esta relação nos termos da decolonialidade, acionando algumas de suas ferramentas analíticas. A colonialidade do saber é uma das ferramentas centrais, considerada como uma estratégia que controla o conhecimento por todo o globo desde o início da modernidade, impondo uma episteme particular como universal e padrão a ser seguido. Muitos estudos sobre as causas e as consequências da modernidade já foram produzidos, porém, os do giro decolonial entretecem uma analítica particular e inovadora. Entre os intelectuais que integram esta comunidade de argumentação está Walter Mignolo, semiólogo argentino que tem se dedicado a compreender a episteme moderno/colonial e seus efeitos políticos, epistêmicos e éticos na América Latina.

Para Mignolo (2008), a modernidade não é um marco temporal, um período histórico do qual não possamos escapar, mas sim, a narrativa de um período histórico elaborado por aqueles que se perceberam como os reais protagonistas, os europeus. Mignolo (2007) representa a modernidade como uma hidra de três cabeças, argumentando que apenas uma delas é visível: a retórica salvacionista. As outras duas cabeças são ocultadas, por serem o 
lado obscuro da modernidade: o domínio territorial e a racialização epistêmica, finalidades últimas da colonialidade.

O domínio colonial das Américas contou com a lógica das colonialidades (colonialidade do poder, colonialidade do saber, colonialidade do ser e a colonialidade de gênero), que operam em vários domínios, como: o econômico, controlando territórios e riquezas naturais; o político, controlando a autoridade; o subjetivo, controlando os corpos etnia, gênero e sexualidade; e o epistêmico, por meio do controle do conhecimento e das culturas. Nesta cartografia, as colonialidades constituíram a modernidade, garantindo a continuidade da acumulação do capital e definindo as regras do jogo científico, suas bases e seus fundamentos (RIBEIRO, 2019).

A colonialidade do saber foi imposta nas nações colonizadas por meio da violência epistêmica, uma ação planejada com a finalidade de constituir o conhecimento a partir da negação de qualquer conhecimento diferente do europeu e de subjetivar os povos colonizados a partir do centro (MIGNOLO, 2007; 2008). Nestes pouco mais de 500 anos, esta lógica de domínio sofreu mudanças superficiais, de modo que a violência epistêmica segue impondo a episteme moderno/colonial, ancorada em três pilares: a teologia cristã dos países ibéricos, a egologia cartesiana e a teoria política ilustrada - liberalismo e marxismo. Segundo Mignolo (2005; 2007), é assim em razão da experiência colonial ter sido ignorada por Descartes e por Marx não ter articulado raça e classe na leitura dos problemas econômicos.

A episteme moderno/colonial foi entretecida nesta rede quando a Europa, sem um imaginário próprio, naturalizou as colonialidades, produzindo a diferença colonial, transformando certas diferenças em valores. Os conhecimentos produzidos pela teologia cristã, pela egologia cartesiana e pela teoria política ilustrada ocultaram a localização geohistórica e a racialização epistêmica, por meio de uma política de conhecimento fundamentada no apagamento dos territórios e da cosmovisão nativa como forma de garantir a universalidade do conhecimento (MIGNOLO, 2008). Mesmo camuflada pelo universalismo abstrato, a colonialidade do saber precisa da retórica salvacionista para justificá-la, devido as desigualdades se constituirem em incômodos problemas resultantes da aventura colonial e que são de difícil solução. A retórica salvacionista distrai a atenção da violência epistêmica disseminando discursos de elogio e de enaltecimento à modernidade, por seus supostos benefícios, como o progresso, a democracia, a liberdade e a felicidade para todos, considerados como iguais em todo o globo.

Ao defender o universalismo abstrato, a colonialidade do saber dissemina o eurocentrismo, que não diz respeito a um local geográfico, mas a hegemonia de uma forma de 
pensar, o padrão ouro que as nações colonizadas devem seguir para serem consideradas civilizadas. O universalismo abstrato foi sedimentado no ocidente pela teologia, pela Filosofia e pelas Ciências Sociais - esta durante o século XIX -, campos de saber em nada assépticos que emprestaram conceitos e categorias de pensamento para serem usados como armas para impor representações das Américas como bárbaras, mutilar o pensamento e silenciar as vozes nativas; em uma palavra, racializar. Assim fazendo, a colonialidade do saber promoveu a exotização e a fetichização da diferença, impondo os valores coloniais aos povos nativos, adormecendo a ferida colonial, anulando a dor com uma variedade de analgésicos.

Ressaltei que a lógica de racialização possui duas dimensões, a epistêmica e a ontológica, com o propósito de classificar como inferiores os povos colonizados, por sua suposta dificuldade cognitiva para produzir conhecimento. Tal dificuldade cognitiva seria atestada pelo fato destes povos não dominarem a escrita, não serem cristãos e não falarem uma das seis línguas imperiais modernas (português, inglês, francês, italiano, alemão, espanhol); por isso, as línguas nativas são consideradas estranhas e/ou inaptas para o pensamento racional (teológico ou secular). Com esta certeza, a racialização epistêmica hierarquizou saber e conhecimento, ao afirmar que os povos das Américas produziam e produzem sabedoria, e a Europa produzia e produz conhecimentos válidos universalmente (MIGNOLO, 2007). Por seu turno, a racialização ontológica reduziu distintos grupos étnicos das Américas a índios e negros, disseminando discursos de que estes não são parte da história e da humanidade, ou melhor, da humanidade propriamente dita: branca, civilizada e cristã.

A cumplicidade entre a colonialidade do saber e a política de estado de conhecimento foi disfarçada pela "identidade disciplinar", expressa pelo fato de que na América Latina ainda pensamos, analisamos, sentimos, descrevemos e escrevemos a partir de excessiva obediência aos conceitos, categorias, axiomas e métodos europeus, com sua cosmovisão monotópica e hermeticamente fechada (MIGNOLO, 2003; 2005; 2008).

Por conta disso, o debate sobre a episteme moderno/colonial é central para a compreensão do Estado moderno e sua estrutura organizativa, pois este foi fundado e legitimado "[...] sob a ilusão de que era um estado neutro, objetivo e 'democrático' separado da identidade em política" (MIGNOLO, 2008, p. 297). Longe de ser asséptico, o estado é articulado por uma pesada burocracia que garante a disciplina e o controle subjetivo de seus agentes estatais e da população. Assim, na contemporaneidade, o estado neoliberal e globalizado privilegia a continuação do modelo epistêmico europeu, o que é garantido por meio da mentalidade burocrática de seus agentes, responsáveis por definir o conhecimento oficial, em geral, expresso em uma política do conhecimento descontextualizada. 
Com estes argumentos, Mignolo (2005; 2008) contesta a sujeição epistêmica, destacando ainda que os gregos inventaram o pensamento filosófico, mas não o pensamento. Assim, o semiólogo argentino se coloca a favor do desprendimento da episteme moderno/colonial, indicando uma rota epistêmica localizada no reservatório das cosmologias nativas desqualificadas nestes mais de 500 anos. Caso permaneçamos presos na episteme hegemônica não visualizaremos outro modo de pensar-fazer-viver na América Latina. A desobediência epistêmica é, portanto, uma responsabilidade política, científica e ética no fazer intelectual em nossa região, que tem registrado uma crescente energia de resistência e de desprendimento da episteme moderno/colonial, tomando forma em pensamentos e ações decoloniais.

Entretecendo o debate epistêmico no campo educativo, Castro-Gómez (2007), filósofo colombiano, argumenta que o conhecimento produzido e ensinado na universidade é herança dos paradigmas coloniais que ao assemelhar a ciência moderna a Deus, transformou-a em verdade universal e absoluta. Este modelo epistêmico tem incidido nos currículos das universidades, de modo que o conhecimento tem sido organizado em uma estrutura disciplinar, arbórea e canônica. Arbórea em razão da ideia de que há hierarquia entre os conhecimentos especializados, diferenciados por fronteiras epistêmicas que não devem ser ultrapassadas. É assim devido ao fim último do conhecimento não ser a apreensão do desconhecido, mas a decomposição da realidade em fragmentos para dominá-la mais e melhor. Em sendo assim, as disciplinas materializam a ideia de que a realidade precisa ser fragmentada, para que as partes possam ser intensamente analisadas na permanente busca de certeza, do conhecimento verdadeiro que está localizado no âmbito incorpóreo, no cogito.

Ainda para o filósofo colombiano, Descartes destaca que tudo o que advém da experiência corporal - os odores, os sabores, as cores -, se constitui em obstáculo epistemológico, logo, devem ser expulsos do espaço científico; esta é uma solução que condena estes conhecimentos a habitarem a doxa (CASTRO-GÓMEZ, 2007). Observados deste ponto de vista, os conhecimentos ancestrais e as tradições culturais nativas são vistos como doxa, como um obstáculo epistemológico a ser superado, por serem considerados exóticos, anedóticos, superficiais, folclóricos, mitológicos, em uma palavra, pré-científicos. Este binarismo erige fronteiras culturais intransponíveis que consolidam a homogeneização. Outro dispositivo que fixa os conhecimentos em certos lugares para facilitar sua identificação e manuseio é o cânone, materializado por meio de hábeis estratégias presentes em todas as disciplinas. Entre as estratégias que definem o que merece constar como conhecimentos válidos estão: retomar as origens de certa disciplina, destacar seus pais fundadores, os autores 
que precisam ser lidos (os clássicos), ou ainda, indicar os temas fundamentais que pertencem unicamente a certas disciplinas. Como é possível notar, a episteme moderno/colonial não afeta unicamente a organização do currículo, afeta as culturas e os sujeitos.

Palermo (2014), também contribui com o debate sobre a relação entre conhecimento, culturas e educação, porém, destacando outro elemento da episteme moderno/colonial, o pensamento único. A imposição do pensamento único exercida pela colonialidade epistêmica impregna todos os âmbitos da vida cotidiana, materializada no terreno da educação em todos os níveis, da educação infantil a pós-graduação, em um sistema que se retroalimenta, sedimentando distinções por meio de diversas estratégias, como a desconsideração de conhecimentos nativos e a produção de subjetividades enjauladas. Neste panorama, tem sido recorrente o descompasso entre discursos e ações pedagógicas, pois o mais comum é a indolência e a improdutividade do discurso das instituições educacionais, na medida em que operam para impedir efetivas mudanças na concepção de conhecimento e nas práticas educativas.

Explorando a política de curriculum, Palermo (2014) informa que desde seu surgimento na Europa, no século XIX, sua finalidade foi formar o/a cidadão/ã para as nações republicanas nascentes, por meio de planos e programas que anulavam os conhecimentos das nações preexistentes. Na contemporaneidade, o pensamento único em educação se manifesta na imposição do livre mercado e nas ações uniformizadoras que silenciam as comunidades tradicionais e invisibilizam o outro, em razão da vergonha de sua cultura supostamente rude, de sua linguagem "terrível", o que gera surdez a hegemônica relativa as suas vozes e demandas culturais. Diante de tais ações e intenções, é preciso relativizar o currículo oficial, universal e homogêneo, para reagir na perspectiva da decolonialidade do conhecimento, um possível caminho para a necessária afetividade e empatia com a memória sociocultural de pertencimento e com os conhecimentos ancestrais. Para Palermo (2014), não se trata de deixar de teorizar, mas de fazê-lo a partir de outro lugar, descartando algumas ferramentas da episteme moderno/colonial, ousando mapear outras experiências e discursos para a reinterpretação das culturas locais, pois a pedagogia ocidental é incapaz de dar conta das diferenças devido às suas finalidades homogeneizadoras.

Neste sentido, o Estado precisa atuar na construção de uma sociedade plural em todas as dimensões, a exemplo de outros países da América Latina. Se trata de um posicionamento ético e político diante da desumanização globalizada e da imposição do pensamento único na economia, na episteme e na educação. Uma ação pedagógica outra, que altere a subjetividade pedagógica eurocêntrica, as representações inferiorizadas da cultura local e do conhecimento 
é demandada, já que a escola tem se limitado a disseminar discursos sobre flexibilidade disciplinar e diversidade, mas ao não promover o diálogo amplo, ao não ouvir as comunidades tradicionais, produz e reproduz ideias e ações excludentes.

\section{A desobediência epistêmica para uma política curricular outra}

Não se pode matar as ideias: elas sobrevivem nos corpos, pois são parte da vida. Walter Mignolo (2014).

A política curricular do estado do Pará impõe às crianças, jovens, professores e professoras, um conhecimento organizado na clássica estrutura disciplinar, arbórea e canônica, objetivando a homogeneização da cultura e a garantia de acumulação incessante no sistema-mundo moderno/colonial contemporâneo. Para distender o debate sobre outro modo de organizar o conhecimento, me aproprio, mais uma vez, das contribuições de Mignolo (2005), Castro-Gómez (2005a; 2005b; 2007) e Palermo (2014), com a única intenção de lançar pistas para movimentar o pensamento na direção da desobediência epistêmica.

Mignolo (2005) aponta a necessidade de aprender a desaprender e a reaprender. Mas aprender a desaprender e a reaprender o quê? Aprender a desaprender os conhecimentos eurocêntricos que, recontextualizados em conteúdos escolares, produzem e reproduzem as representações estereotipadas e inferiorizadas sobre as culturas e os conhecimentos nativos, para reaprender a ser e a viver em diálogo com a diferença. O conhecimento orientado pelos princípios éticos, políticos e culturais do giro decolonial precisa ser produzido a partir do desmonte das quatro colonialidades, de modo a permitir que crianças e jovens da escola básica identifiquem a ferida colonial, reconheçam a racialização, as representações inferiorizadas e o eurocentrismo para questioná-los, potencializando habilidades para pensar a partir da política do lugar e da interculturalidade, ferramentas capazes de auxiliar no desafio de pensar uma justa seleção de conhecimento para a América Latina e para a Amazônia.

A política do lugar é um processo de reconhecimento da violência colonial do passado e do presente, para se dar conta da localidade geo-histórica e da fratura de viver no Sul global; é capaz de incitar o pensar-fazer-sentir desde o reconhecimento da história, das memórias e dos conhecimentos ancestrais, para constituir identidades e subjetividades decoloniais. A América Latina é um lugar de culturas vivas, produzidas por mulheres e homens que reagem e lutam em busca de alternativas para as políticas coloniais e pelo bem viver na região (MIGNOLO, 2005). Já a interculturalidade nasceu nos Andes e é uma noção introduzida por intelectuais indígenas para reivindicar direitos epistêmicos no contexto dos 
projetos coloniais ${ }^{6}$. Inter-cultura significa inter-epistemologia, um diálogo intenso entre a cosmologia não-ocidental (afros, indígenas, mestiças, asiáticas, árabe-islâmicos, entre outras) e a ocidental. O diálogo intercultural é uma estratégia ético-política que coloca em cena tanto a razão universal quanto a razão local, promovendo a episteme mestiça constituindo sujeitos outros, capazes de ler e traduzir o encontro colonial e seus efeitos.

Quanto à rígida e compartimentada estrutura disciplinar do conhecimento nas instituições educativas, Castro-Gómez (2005a; 2007) evidenciou antes a genealogia deste modus operandi que reverbera na educação. Considerando que vivemos em um mundo complexo, a prática interdisciplinar exaustivamente proposta como forma de superar a compartimentação não alcança seu intento, pois se limita a trocar informações entre diferentes disciplinas, deixando intactos seus fundamentos. A ação capaz de desfragmentar a compartimentação e promover o diálogo entre os conhecimentos e entre culturas é a transdisciplinar, uma episteme emergente que se torna ponte para o diálogo transcultural entre conhecimentos, auxiliando o intercâmbio cognitivo entre ciência ocidental e conhecimentos nativos. Neste sentido, a transdisciplinaridade é capaz de intervir na estrutura disciplinar, arbórea e canônica, permitindo experimentações de estruturas rizomáticas, manifestas em redes disciplinares e/ou ensaios transculturais.

No Brasil, historicamente o currículo tem sido narrado pelo colonizador e subordinado ao cânone europeu transmitindo conhecimentos supostamente objetivos, o que tem efeitos cruéis nas identidades e subjetividades de crianças e jovens (COSTA, 1998). Porém, há algumas propostas educativas em movimento, como a educação bilíngue para a escola indígena, a educação quilombola, a educação nos espaços dos movimentos sociais, como a proposta pelo Movimento Sem-Terra. Neste terreno aberto, é preciso seguir tensionando para distender o espaço curricular, desafiando a estrutura disciplinar, o cânone e o monoculturalismo das políticas curriculares nacional e local, propondo outra forma de organizar o conhecimento.

Concluo argumentando que o currículo como arena de produção de significados, terreno de lutas entre teorias e visões de mundo, permite negociações entre os interesses do Estado e da sociedade civil, caso se tenha em mente o equilíbrio entre conhecimentos científicos e conhecimentos ancestrais. Uma política curricular que recuse a objetificação do lugar, do outro e dos conhecimentos ancestrais, que avance para além da retórica da

\footnotetext{
${ }^{6}$ A interculturalidade difere do multiculturalismo, considerado por Mignolo (2005) como um produto do Estado americano/EUA, que tem o objetivo de conceder "cultura" mantendo a episteme européia.
} 
valorização da diversidade, das práticas interdisciplinares e da participação, precisa promover redes interculturais e transdisciplinares de conhecimentos.

\section{Considerações provisórias}

A etnografia multilocal foi a arte do fazer que permitiu seguir o discurso, as metáforas e a trama do Documento Curricular do Estado do Pará, identificando conflitos e resistências. Foi possível seguir dois traços marcantes do DCEPará que tornaram esta proposta curricular inconsistente, na medida em que mantém a clássica estrutura disciplinar, arbórea, canônica e homogeneizadora, apesar de sua crítica à compartimentação do conhecimento e de discursos sobre diversidade e participação, porém, como afirmei, a sociedade civil organizada e as comunidades tradicionais foram excluídas do processo de elaboração do documento curricular. No fim, esta política curricular traduz os anseios políticos de grupos hegemônicos internos e externos ao país que almejam manter a identidade disciplinar com a episteme moderno/colonial e apagar as culturas minoritárias do mapa do sistema-mundo.

Nos termos do giro decolonial, o DCEPará expressa uma política de Estado de conhecimento obediente a episteme moderno/colonial, em razão dos agentes estatais terem se comprometido com a demandas do sistema-mundo. Apesar da breve contextualização, da noção de currículo como construção social ser coerente com certa crítica a compartimentação do saber, da indicação de quebrar o olhar ao visualizar o conhecimento moderno, de buscar visibilizar os saberes populares, a estrutura disciplinar, arbórea e canônica e a homogeneização cultural o tornam inconsistente.

Outra organização do conhecimento é possível, contudo, é imperativo praticar a desobediência epistêmica, uma reação capaz de desarticular a compartimentação, o cânone e a homogeneização excludentes. Não se trata de produzir conhecimentos a partir de uma simples desvinculação da episteme colonial, mas de intervincular racionalidades diferentes para restituir histórias, memórias e subjetividades colonizadas, por meio do diálogo transdisciplinar e intercultural. A partir das pistas aqui colocadas pelo giro decolonial, visualizo a possibilidade de um currículo decolonial capaz de incitar o diálogo intercultural entre conhecimentos ocidentais e conhecimentos ancestrais, para recontextualizá-los em conhecimentos escolares para um pensar-fazer-viver outro na América Latina e na Amazônia.

\section{REFERÊNCIAS}


ABRAMS, P. Notas sobre la dificultad de estudiar el estado. In: ABRAMS, P.; GRUPTA, A.; MITCHELL, T. (Eds.). Antropología del estado. México: FCE, 2015.

BRASIL. Ministério da Educação. Base Nacional Comum Curricular. Brasília, DF: MEC, 2018.

CASTRO-GÓMEZ, S. Ciências sociais, violência epistêmica e o problema da invenção do outro. In: LANDER, E. (Org.). A colonialidade do saber: eurocentrismo e ciências sociais 1perspectivas latino-americanas. Buenos Aires: CLACSO, 2005a.

CASTRO-GÓMEZ, S. La Hybris del punto cero: ciencia, raza y ilustración en la nueva granada (1750-1816). Bogotá: Pontificia Universidad Javeriana, 2005 b.

CASTRO-GÓMEZ, S. Decolonizar la universidad. La hybris del punto cero y el diálogo de saberes. In: CASTRO-GÓMEZ, S.; GROSFOGUEL, R. (Comp.). El giro decolonial: reflexiones para una diversidad epistémica más allá del capitalismo global. Bogotá: Siglo del Hombre Editores, 2007.

COSTA, M. V. Currículo e política cultural. In: COSTA, M. V. (Org.). O currículo: nos limiares do contemporâneo. Rio de Janeiro: DP\&A,1998.

FRANCO, S. A. P. O cânone literário no material didático do Ensino Médio. 2008. Disponível em: http://www.gestaoescolar.diaadia.pr.gov.br/arquivos/File/producoes_pde/ artigo_sandra_aparecida_pires_franco.pdf Acesso em: 05 out. 2019.

GABRIEL, C. T. Quando "nacional" e "comum" adjetivam o currículo da escola pública. Revista Retratos da Escola, Brasília, v. 9, n. 17, p. 283-297, jul./dez., 2015.

LOPES, A. C. Porque somos tão disciplinares? Educação Tempo Digital, Campinas, v. 9, n. esp., p. 201-212, out., 2008.

LOPES, A. C. Itinerários formativos na BNCC do Ensino Médio: identificações docentes e projetos de vida juvenis. Revista Brasileira de Educação, Rio de Janeiro, v. 13, p. 59-75, jan./mai., 2019.

LOPES, A. C. Políticas curriculares: continuidade ou mudança de rumos? Revista Brasileira de Educação, Rio de Janeiro, n. 26, mai./jun./jul./ago., 2004.

MACEDO, E. Base Nacional Comum para currículos: direitos e objetivos de aprendizagem e desenvolvimento para quem? Educ. Soc., Campinas, v. 36, n. 133, p. 891-908, out./dez., 2015.

MACEDO, E. Base Nacional Curricular Comum: novas formas de sociabilidade produzindo sentidos para educação. Revista e-Curriculum, São Paulo, v. 12, n. 3, p. 1530-1555 out./dez., 2014.

MARCUS, G. Etnografía en/el sistema mundo: el surgimento de la etnografia multilocal. Alteridades, Ciudad de México, v. 11, n. 22, p. 111-127, 2001. 
MARCUS, G.; FISHER, M. La antropología como crítica cultural: um momento experiemental en las ciencias humanas. Buenos Aires: Amorrortu Editories S.A., 2000.

MIGNOLO, W. Histórias locais/projetos globais: colonialidade, saberes subalternos e pensamento liminar. Belo Horizonte: Ed. UFMG, 2003.

MIGNOLO, W. A colonialidade de cabo a rabo: o hemisfério ocidental no horizonte conceitual da modernidade. In: LANDER, E. (Org.). A colonialidade do saber: eurocentrismo e ciências sociais: perspectivas latino-americanas. Buenos Aires: CLACSO, 2005.

MIGNOLO, W. La idea de America Latina: la herida colonial y la opción decolonial. Barcelona: Gedisa, 2007.

MIGNOLO, W. Desobediência epistêmica: a opção descolonial e o significado de identidade em política. Revista Gragoatá, Niterói, n. 22, p. 11-41, 2008.

MIGNOLO, W. Retos decoloniales, hoy. In: BORSANI, M. E. B.; QUINTERO, P. (Comp.). Los desafíos decoloniales de nuestros días: pensar en colectivo. 1. ed. Neuquén: EDUCO/Universidad Nacional del Comahue, 2014.

MUZZOPAPPA, E.; VILLALTA, C. Los documentos como campo: reflexiones teóricometodológicas sobre un enfoque etnográfico de archivos y documentos estatales. Revista Colombiana de Antropología, Bogotá, v. 47, n. 1, p. 13-42, 2011.

PALERMO, Z. Irrupción de saberes "otros" en el espacio pedagógico: hacia una "democracia decolonial”. In: BORSANI, M. E. B.; QUINTERO, P. (Comp.). Los desafíos decoloniales de nuestros días: pensar en colectivo. 1. ed. Neuquén: EDUCO/Universidad Nacional del Comahue, 2014.

PARÁ. Conselho Estadual de Educação. Documento Curricular do Estado do Pará. Belém: CEE, 2018.

RIBEIRO, J. O. S. Produção generificada do brinquedo de miriti: marcas de colonialidade. Revista Cocar. Belém, v. 13, n. 25, p. 136-159, jan./mar., 2019.

SILVA, T. T. Documentos de identidade: uma introdução às teorias do currículo. Belo Horizonte: Autêntica, 1999.

TIRIBA, L.; FLORES, M. L. R. A educação infantil no contexto da base nacional comum curricular: em defesa das crianças como seres da natureza, herdeiras das tradições culturais brasileiras. Debates em Educação, Maceió, v. 8, n. 16, jul./dez., 2016.

WALLERSTEIN, I. Análisis de sistemas-mundo: una introdución. Buenos Aires: Seiglo Vintiuno editores, 2004.

WEBER, M. Economia e sociedade: fundamentos da sociologia compreensiva. Trad. Regis Barbosa e Karen Elsabe Barbosa. São Paulo/Brasília: Editora UnB, 1999. v. 2. 
ZABALA, M. E. Hacer estudios etnográficos en archivos sobre hechos sociales del pasado. La reconstrucción de la trayectoria académica y religiosa de Monseñor Pablo Cabrera a través de los archivos de la ciudad de Córdoba. Tabula Rasa, Bogotá, n. 16, p. 265-282, jan./jun., 2012.

ZARIAS, A. Os tempos da etnografia, da pesquisa em arquivos e processos judiciais. Anais do Seminário Quando o campo é o arquivo: etnografias, histórias e outras memórias guardadas, Rio de Janeiro, 2004. Rio de Janeiro: CPDOC/LAH/IFCS/UFRJ, 2004.

\section{Como referenciar este artigo}

SEIXAS RIBEIRO, J. O. Seguindo os traços da episteme moderno/colonial no Documento Curricular do Estado do Pará. Revista Ibero-Americana de Estudos em Educação, Araraquara, v. 16, n. 3, p. 1878-1897, jul./set. 2021. e-ISSN: 1982-5587. DOI: https://doi.org/ 10.21723/riaee.v16i3.13277

Submetido em: 03/02/2020

Revisões requeridas em: 27/11/2020

Aprovado em: $16 / 12 / 2020$

Publicado em: 01/07/2021 